\title{
Is the high-performance thermoplastic polyetheretherketone indicated as a clasp material for removable dental prostheses?
}

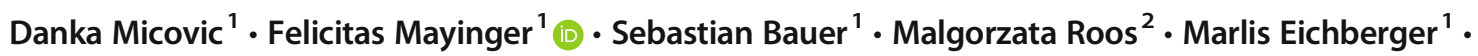 \\ Bogna Stawarczyk ${ }^{1}$
}

Received: 23 April 2020 / Accepted: 23 September 2020 / Published online: 7 October 2020

(C) The Author(s) 2020

\begin{abstract}
Objectives To investigate the retention force of polyetheretherketone (PEEK) removable dental prosthesis clasps in comparison with a cobalt-chrome-molybdenum control group after storage in artificial saliva.

Materials and Methods Clasps were milled (Dentokeep (PEEKmilled1), NT digital implant technology; breCAM BioHPP Blank (PEEKmilled2), bredent), pressed (BioHPP Granulat for 2 press (PEEKpressed), bredent), or cast (remanium GM $800+$ (cobalt-chrome-molybdenum), Dentaurum); $N=60, n=15$ /subgroup. Retention force was examined 50 times/ specimen in a pull-off test using the universal testing machine (Zwick 1445), where pull-off force was applied with a crosshead speed of $5 \mathrm{~mm} /$ minute until the maximum force dropped by $10 \%$, at different aging levels: (1) initial, after storage in artificial saliva for (2) 90 and (3) 180 days. Statistical analysis was performed using one-way ANOVA followed by post hoc Scheffé-test and mixed models $(p<0.05)$.

Results Cobalt-chrome-molybdenum presented the highest retention force. No differences were observed between polyetheretherketone materials. Cobalt-chrome-molybdenum showed a significant decrease of its values after artificial aging, while polyetheretherketone materials presented similar results over the course of aging. Regarding a repetitive insertion and removal, even though PEEKmilled2 and cobalt-chrome-molybdenum showed an initial increase, ultimately, a decrease in retention force was observed for all tested groups.

Conclusions Although the control group showed significantly higher results, the retention force of polyetheretherketone materials indicate a potential clinical application. Neither the manufacturing process nor artificial aging showed an impact on the retention force of polyetheretherketone clasps.

Clinical relevance Mechanical properties of novel removable dental prosthesis clasp materials devised to meet the growing esthetic demands of patients need to be investigated to ensure a successful long-term clinical application.
\end{abstract}

Keywords PEEK $\cdot$ Cobalt-chrome-molybdenum $\cdot$ Clasp $\cdot$ Removable dental prosthesis $\cdot$ Retention force

Danka Micovic and Felicitas Wiedenmann contributed equally to this work.

Felicitas Mayinger

felicitas.wiedenmann@med.uni-muenchen.de

1 Department of Prosthetic Dentistry, University Hospital, LMU Munich, Goethestraße 70, 80336 Munich, Germany

2 Department of Biostatistics, Epidemiology, Biostatistics and Prevention Institute, University of Zurich, Hirschengraben 84, 8001 Zurich, Switzerland

\section{Introduction}

Due to recent leaps in implant and restorative dentistry, fixed dental prostheses (FDPs) allow highly esthetic results for a wide majority of patients. In some cases, an extensive replacement of missing teeth does, however, still require treatment with removable dental prostheses (RDPs) because of reduced health, challenging anatomical situations, physiology, or financial reasons [1].

Clasps can be used as retention elements to attach a prosthesis to the remaining teeth, thus ensuring functional stability during enunciation and mastication. In the course of time, a wide variety of clasps have been designed to tailor to various indications. Clasps traditionally consist of a retentive arm that 
passes over the prosthetic equator and comes to a rest in an undercut, while the reciprocal arm undertakes the task of opposing lateral forces during insertion and removal [2]. The depth of the undercut as well as the elastic modulus of the clasp material directly affects the retention of RDPs [3].

Metal alloy has for a long time been the material of choice for RDP clasps, as its outstanding mechanical properties are well documented [4-12]. The alloy most commonly used is cobalt-chrome-molybdenum (CoCrMo) [13]. Numerous studies have observed significantly higher retention load values of CoCrMo clasps than seen for alternative materials such as titanium $[11,12]$. With ever rising esthetic demands, research activities have focused on tackling the main drawback of alloy clasps: their metallic color. To eliminate the esthetically disadvantageous retentive arm, lingual retentions or rotational paths were investigated as alternatives to conventional clasp designs $[14,15]$. Others aimed to modify the alloy claps itself by etching and veneering said materials with tooth-colored resin composite [16].

One relatively new approach is to manufacture clasps of a tooth-colored thermoplastic material, such as polyoxymethylene [17], polycarbonate and polyamide [3], or polyaryletherketone (PAEK) [18]. The term "PAEK" comprises a number of closely related high-performance thermoplastics, from polyetheretherketone (PEEK) over polyetherketoneketone (PEKK) to aryl ketone polymer (AKP), that convince with notable mechanical properties and manifold applications in the field of dentistry $[19,20]$. In prosthodontics, PEEK is employed as a framework material for fixed and removable dental prostheses and the manufacturing of clasps and implant abutments [21, 22]. PEEK may also hold a promising future in dental implantology. While unmodified PEEK is less osseoconductive and bioactive than titanium [23], dental implants made from PEEK have been shown to exhibit less stress shielding when compared with titanium [21]. Studies have furthermore observed a high biocompatibility and chemical stability of PEEK to both organic and inorganic chemicals $[24,25]$. This finding is of special importance for patients prone to allergies. In a dental technical laboratory, PEEK can be processed by pressing the extruded material with a special vacuum-pressing device. For this purpose, PEEK is used either as pellets or in its granular form. Computer-aided design (CAD) and computer-aided manufacturing (CAM) technology enable an alternative manufacturing process by milling PEEK restorations from prepressed blanks. The industrial prepressing of blanks has been observed to increase the stability and reliability of PEEK restorations [26]. While all these fabrication methods allow using the same raw PEEK material, results of mechanical stress tests for these materials are very limited $[19,26]$ and the available literature varies considerably in terms of the investigated prosthetic applications.
Therefore, the aim of this study was to examine the retention force of RDPs' clasps made from three different PEEK materials in comparison with a CoCrMo control group after storage in artificial saliva. One important aspect when conducting an in vitro study is the close approximation to the clinical situation. To test the specimens' long-term performance, artificial aging was thus included in the study design [27]. The study tested the null hypothesis that neither the clasp material, the different manufacturing processes for the PEEK clasps, artificial aging, nor a repetitive insertion and removal of the clasps on an abrasion-resistant CoCrMo model showed an impact on the retention force.

\section{Materials and methods}

The retention force of RDP clasps made from three differently manufactured PEEK materials (Dentokeep (abbreviation: PEEKmilled1), NT digital implant technology, Karlsruhe, Germany; breCAM BioHPP Blank (PEEKmilled2) and BioHPP Granulat for 2 press (PEEKpressed), bredent, Senden, Germany) and a CoCrMo alloy (control group; remanium GM 800+ (CoCrMo), Dentaurum, Ispringen, Germany) was examined in a pull-off test at different aging levels (Table 1, Fig. 1).

\section{Specimen fabrication}

To produce $15 \mathrm{RDP}$ clasp specimens from each material $(N=$ 60; $n=15$ /subgroup; Fig. 2), a hollow form for a Bonwill clasp was prepared between the second pre- and first molar of a dental arch model (Frasaco Mandible 119, A-3, Franz Sachs \& Co, Tettnang, Germany). By casting (Globucast, Krupp AG, Essen, Germany) with the lost-wax technique (Finowax, DT, Bad Kissingen, Germany), a master clasp was fabricated from CoCrMo (remanium GM $800+$ ). To allow for a later positioning in the pull-off test, the casting channel, which had been positioned in the insertion direction of the Bonwill clasp, was cut at a height of $15 \mathrm{~mm}$. The model specimen was subsequently air-particle abraded (basis Quattro IS, Renfert, Hilzingen, Germany) with $110 \mu \mathrm{m}$ $\mathrm{Al}_{2} \mathrm{O}_{3}$ (Korox 110, Bego, Bremen, Germany) at $0.2 \mathrm{MPa}$ and polished with a silicone polisher and a polishing brush (Komet, Gebr. Brasseler GmbH \& Co. KG, Lemgo, Germany). A master STL file (Table 2) was then created by scanning (Ceramill map 300, Amann Girrbach, Koblach, Austria) the model CoCrMo specimen.

Employing CAM software (Zenotec CAM, V2.2.017, Wieland Dental + Technik, Pforzheim, Germany) and a milling machine (i-Mes 4030, Wieland Dental + Technik), PMMA (Zeno PMMA cast Disc, Wieland Dental + Technik; $n=30$ ) and PEEK (Dentokeep and breCAM; $n=15 /$ subgroup) clasps were manufactured. 
Table 1 Materials, abbreviations, Young's modulus, manufacturers, compositions, and lot. no. used

\begin{tabular}{|c|c|c|c|c|c|}
\hline Material & Abbreviations & $\begin{array}{l}\text { Young's } \\
\text { modulus }\end{array}$ & Manufacturers & Compositions & Lot. no. \\
\hline Dentokeep & PEEKmilled1 & $4 \mathrm{GPa}$ & $\begin{array}{l}\text { NT digital implant technology, } \\
\text { Karlsruhe, Germany }\end{array}$ & $\begin{array}{l}\text { Polyether ether ketone, inorganic } \\
\text { fillers }(20 \%)\end{array}$ & 11DK18001 \\
\hline breCAM BioHPP Blank & PEEKmilled2 & $4 \mathrm{GPa}$ & bredent, Senden, Germany & & 380149 \\
\hline BioHPP Granulat for 2 press & PEEKpressed & $4 \mathrm{GPa}$ & & & 379806 \\
\hline remanium GM 800+ & CoCrMo & $230 \mathrm{GPa}$ & Dentaurum, Ispringen, Germany & $\begin{array}{l}\mathrm{Co}(58.3 \%), \mathrm{Cr}(32.0 \%), \mathrm{Mo}(6.5 \%) \\
\text { W }(1.5 \%), \mathrm{Si}(1.0 \%)\end{array}$ & 816 \\
\hline Zeno PMMA cast Disc & & $2.4 \mathrm{GPa}$ & Wieland Dental Pforzheim, Germany & Polymethylmethacrylate & 1304 \\
\hline
\end{tabular}

Afterwards, PMMA clasps were embedded (Brevest for 2 press, bredent) in a muffle according to the manufacturer's instruction (Fig. 3). The investment ring was heated at $8{ }^{\circ} \mathrm{C} /$ s to $630{ }^{\circ} \mathrm{C}$ (ARCA 20, Schütz Dental, Rosbach, Germany) and then cooled to $400{ }^{\circ} \mathrm{C}$. Subsequently, the pre-heated muffle was filled with Granulat and kept in the preheating oven for $20 \mathrm{~min}$. As the next step, Granulat was pressed at $0.45 \mathrm{MPa}$ under vacuum (for 2 press, bredent).

The remaining PMMA clasps were embedded (JET2000, Siladent, Dr. Böhme \& Schöps GmbH, Goslar, Germany) in a similar workflow, before the investment ring was heated at 6 ${ }^{\circ} \mathrm{C} / \mathrm{s}$ to $900{ }^{\circ} \mathrm{C}$ (KaVo EWL 5636, KaVo Dental GmbH, Biberach/Riß, Germany). CoCrMo specimens (remanium GM $800+$ ) were then cast at $1410{ }^{\circ} \mathrm{C}$ with a pressure of $0.45 \mathrm{MPa}$ (Globucast).

After cooling, the investment material was removed from PEEKpressed and CoCrMo specimens using a blasting unit (Fine-blaster type FG 3, Sandmaster, Zofingen, Switzerland) with $105 \mu \mathrm{m} \mathrm{Al}_{2} \mathrm{O}_{3}$ (Hasenfratz) at a pressure of $0.2 \mathrm{MPa}$.

Clasps were subsequently polished with a silicone polisher and a polishing brush (Komet). High gloss was achieved with a goat hairbrush and buffing wheel using polishing paste (Universal-Polierpaste, Ivoclar Vivadent, Ellwangen, Germany). The fit of the clasp specimens on CoCrMo models was adjusted and verified with occlusion foil (Hanel Okklusions-Folie $12 \mu \mathrm{m}$, Coltène/Whaledent AG, Altstätten, Switzerland).

Fig. 1 Study design

\section{Retention force measurement}

Retention force was determined at three different aging levels:

(1) Initial

(2) After storage in artificial saliva for 90 days at $37^{\circ} \mathrm{C}$ in an incubator (Hera Cell 150, Heraeus, Hanau, Germany)

(3) After storage in artificial saliva for 180 days at $37^{\circ} \mathrm{C}$ in an incubator (Hera Cell 150)

Artificial saliva was prepared according to Fusayama Meyer et al. [28] (components: potassium chloride [0.4 g/l], sodium chloride $[0.400 \mathrm{~g} / 1]$, calcium chloride dihydrate [0.906 $\mathrm{g} / \mathrm{l}]$, monosodium phosphate dihydrate $[0.690 \mathrm{~g} / \mathrm{l}]$, sodium sulfide nonahydrate $[0.005 \mathrm{~g} / 1]$, urea $[1.000 \mathrm{~g} / \mathrm{l}] ; \mathrm{pH}=4.7$ ) and replaced every 14 days.

Casting channels/connectors were inserted in an individually manufactured stainless steel adapter (SD Mechatronik GmbH, Feldkirchen, Germany; Fig. 4) after CoCrMo models were positioned in the insertion/removal direction of the Bonwill clasp. Using the universal testing machine (Zwick 1445, Zwick GmbH \& Co. KG, Ulm, Germany), pull-off force was applied in direct extension of the casting channel/ connector with a crosshead speed of $5 \mathrm{~mm} / \mathrm{min}$ until the maximum force dropped by $10 \%$. At the three different aging levels, 50 retention force measurements were performed for each clasp at each aging level.

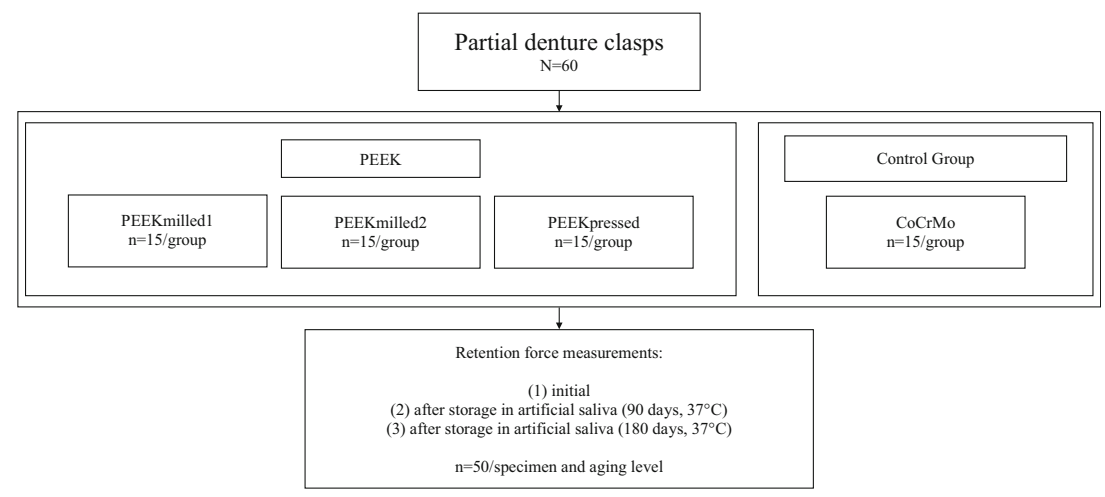




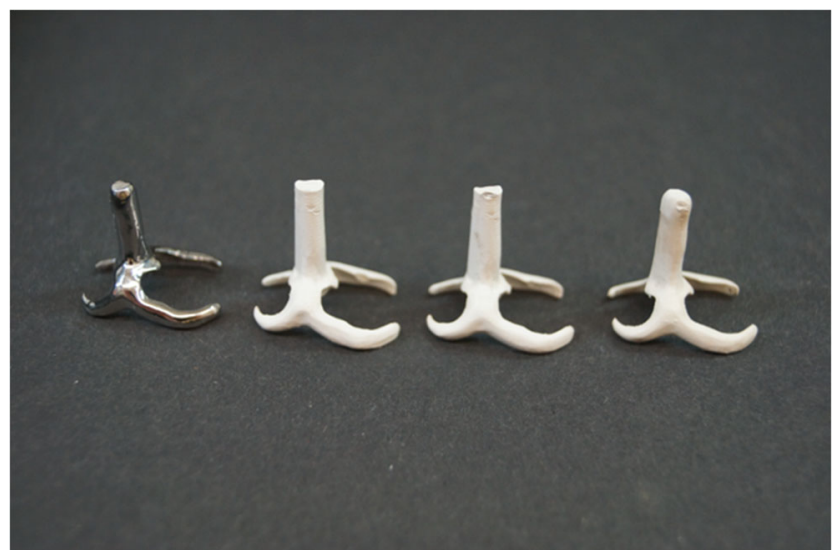

Fig. 2 RDP clasp specimens made of CoCrMo, PEEKmilled1, PEEKmilled2, and PEEKpressed

\section{Statistical analysis}

A power analysis using the retention force values of the control group $(163 \pm 55 \mathrm{~N})$ had been computed using nQuery Advisior (Version 6.04.10, Statistical Solutions, Saugaus Mass, USA) prior to performing this study. Employing a two-group $t$ test with a significance level of $\alpha=0.05$ showed that a sample size of 15 in each group would have a power of $97 \%$ to detect a difference of $81.5 \mathrm{~N}$. Under identical conditions, a Bonferroni correction would have a power of $92 \%$.

A statistical evaluation of the data was performed using descriptive analysis followed by Kolmogorov-Smirnov for testing the violation of normal distribution. To determine the influence of the material and the aging level on the retention force, one-way ANOVA followed by Scheffé post hoc test was computed. Because each clasp was measured 50 times, leading to dependent measurements, linear mixed models were applied to determine global retention force values within the tested groups and potential changes of these values at different aging levels.

All $p$ values below 0.05 were construed as statistically significant. Data were analyzed with SPSS version 25.0 (IBM, Armonk, NY, USA).

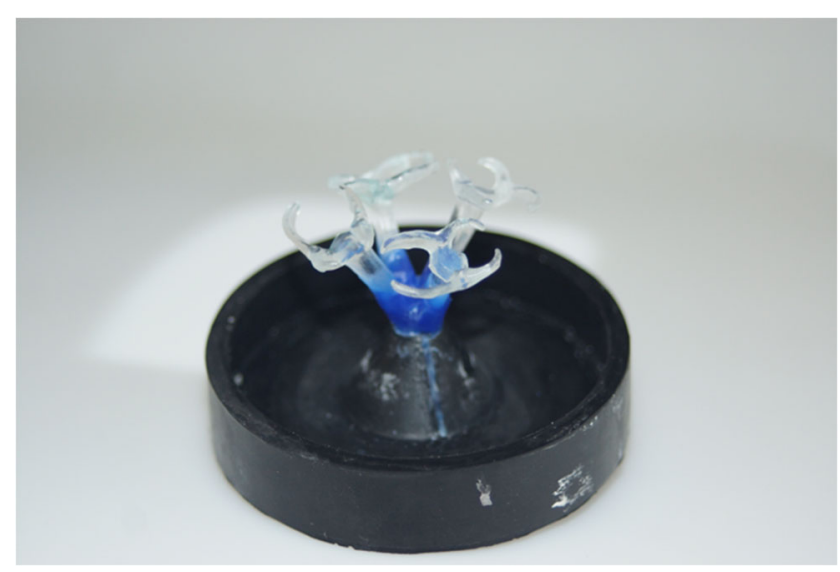

Fig. 3 PMMA clasps prior to embedding during the manufacturing process of PEEKpressed and CoCrMo specimens

\section{Results}

The results of the descriptive analyses are presented in Table 3. Parametric tests were performed, as no violation of normality assumption was indicated.

The choice of clasp material presented a significant impact on the retention force, with the control group showing higher values than the three PEEK materials $(p<0.001)$. No differences in retention force were observed between different PEEK materials $(p=0.412-0.607)$.

Artificial aging showed an influence on the retention force of the different materials, with the control group presenting a significant decrease of its values ( $p<0.01$, Fig. 5). There is no evidence that PEEK materials show any decrease over the course of aging ( $p=0.236-0.401)$.

The repetitive insertion and removal of the clasps led to a reduction of the retention force of PEEKmilled1 $(p<0.001-$ 0.048; Table 4) and PEEKpressed $(p<0.001)$ specimens at all aging levels. For PEEKmilled2 and CoCrMo, an increase of retention force was observed initially $(p<0.001)$, before values decreased with a repetitive insertion and removal of the RDP clasps at the subsequent aging levels $(p<0.001-0.199)$.

Table 2 Dimensions of the Bonwill clasp

\begin{tabular}{llll}
\hline & Length $(\mathrm{mm})$ & Height $(\mathrm{mm})$ & Width (mm) \\
\hline Retentive arm, overall (external dimension) & 19.0 & & \\
Reciprocal arm, overall (external dimension) & 16.2 & & \\
Retentive arm, short (inner dimension) & 4.9 & 2.33 & 1.76 \\
Retentive arm, long (inner dimension) & 10.5 & 2.9 & 1.72 \\
Reciprocal arm, short (inner dimension) & 5.5 & 1.79 & 1.73 \\
Reciprocal arm, long (inner dimension) & 8.7 & 2.91 & 1.89 \\
Support & & 2.0 & 4.8 \\
Connector & & & $4.5 \times 4.92$ \\
\hline
\end{tabular}

Retentive arm (buccal), reciprocal arm (lingual), short arm (premolar), long arm (molar) 


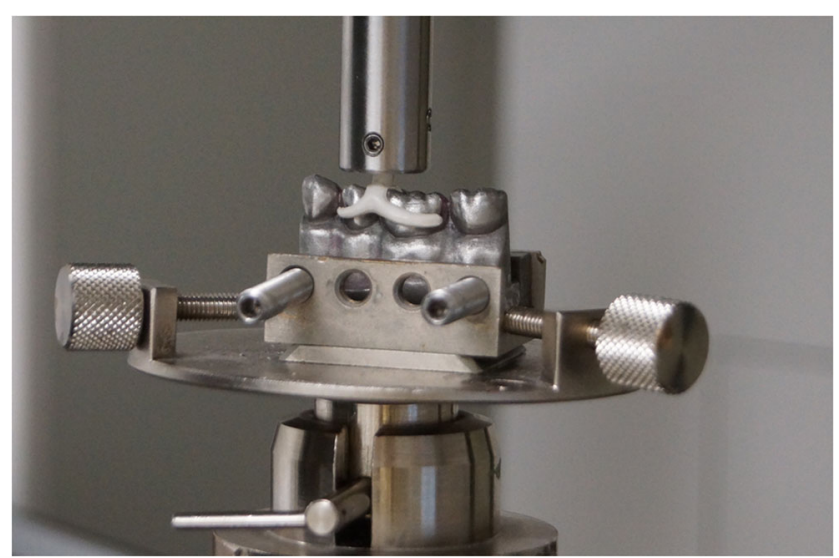

Fig. 4 Retention force measurement (Zwick 1445, Zwick GmbH \& Co. $\mathrm{KG})$

\section{Discussion}

The aim of this study was to examine the retention force of RDP clasps made from different PEEK materials in comparison with a CoCrMo control group after storage in artificial saliva to imitate clinical conditions. The null hypothesis had to be rejected, as the results showed all tested parameters to affect the retention force.

When regarding the choice of clasp material, the control group showed superior retention values compared to the three PEEK materials. These results are in line with previous examinations investigating the retentive force and fatigue resistance of both PEEK and CoCr clasps [18, 29, 30]. Even though PEEK clasps presented lower values, they might provide enough retention for a clinical usage, as they exceed the suggested retention force of 5-10 N per clasp [31, 32]. As excessive retentive forces can overstrain the remaining abutment teeth, especially in periodontally compromised dentitions [33], PEEK materials could represent a valid alternative. As all PEEK materials showed similar results over the course of aging, the manufacturing process does not seem to hold an influence on the resulting mechanical properties. In the present study, two PEEK materials were milled using $\mathrm{CAD} / \mathrm{CAM}$ technology, while one material was pressed. As most dental laboratories nowadays have access to high-end milling machines, this elegant process regarded to be less timeconsuming and prone to manual mistakes should be preferred [34].

Artificial aging also presented an impact on the retention force. The control group showed a high decrease of its values, while PEEK clasps presented similar results before and after the aging process. A high decrease in the retention force of the control group can be explained by alloy corrosion taking place in wet environments, which has previously been reported to lead to a reduced fatigue strength of $\mathrm{CoCr}$ [35]. While the three PEEK materials also presented a decline in retention force, this was not significant. These results are consistent with a previous study investigating the behavior of PEEK during artificial aging with different saliva solutions that reported the thermoplastic to show a great structural stability and little or no impact of varying $\mathrm{pH}$ values on its nanomechanical properties [36].

The repetitive insertion and removal of the clasps led to a reduction of the retention force of PEEKmilled 1 and PEEKpressed specimens at all aging levels. For PEEKmilled 2 and CoCrMo, an increase of retention force was observed initially, before values decreased with a repetitive insertion and removal of the RDP clasps at the subsequent aging levels. An initial increase in retention force might be explained by abrasion phenomena of both the model and clasps resulting in an improved fit of the clasps and in consequence, an increased retention force. A previous examination investigating the retentive force of thermoplastic resins and cobalt-chrome over a simulation period of 10 years reported similar findings with an initial increase in values during the first period of cycling that was later on substituted by a continuous decrease [18]. The elastic modulus plays an important role in fatigue testing, as a material with a high elastic modulus is able to assume its prior structure without permanent deformation. CoCrMo, which possesses a high elastic modulus of $220 \mathrm{GPa}$ [37], should thus in theory be less prone to a decrease in retention force due to a repetitive insertion and removal of the clasps than PEEK, which only holds an elastic modulus of around $4 \mathrm{GPa}$ [38]. In contrast to this idea, a recent study observed polymer-based clasps to act more consistently over

Table 3 Descriptive statistics for the retention force $[\mathrm{N}]$ of the different clasp materials at varying aging levels

\begin{tabular}{|c|c|c|c|c|c|c|c|c|}
\hline \multirow[t]{2}{*}{ Aging level } & \multicolumn{2}{|l|}{ PEEKmilled1 } & \multicolumn{2}{|l|}{ PEEKmilled2 } & \multicolumn{2}{|l|}{ PEEKpressed } & \multicolumn{2}{|l|}{ CoCrMo } \\
\hline & Mean \pm SD & $95 \% \mathrm{CI}$ & Mean \pm SD & $95 \% \mathrm{CI}$ & Mean \pm SD & $95 \% \mathrm{CI}$ & Mean \pm SD & $95 \% \mathrm{CI}$ \\
\hline (1) Initial & $58.1 \pm 18.8^{\mathrm{a}}$ & {$[47.6 ; 68.5]$} & $43.9 \pm 22.6^{\mathrm{a}}$ & {$[31.1 ; 56.4]$} & $50.8 \pm 17.9^{\mathrm{a}}$ & {$[40.8 ; 60.8]$} & $163 \pm 55.2^{\mathrm{b}}$ & {$[132 ; 193]$} \\
\hline $\begin{array}{l}\text { (2) After storage in artificial saliva } \\
\left(90 \text { days, } 37^{\circ} \mathrm{C}\right)\end{array}$ & $43.0 \pm 14.4^{\mathrm{a}}$ & {$[35.0 ; 51.0]$} & $40.3 \pm 20.4^{\mathrm{a}}$ & {$[29.0 ; 51.6]$} & $45.6 \pm 14.9^{\mathrm{a}}$ & {$[37.3 ; 53.9]$} & $127 \pm 40.4^{\mathrm{b}}$ & {$[104 ; 149]$} \\
\hline $\begin{array}{l}\text { (3) After storage in artificial saliva } \\
\left(180 \text { days, } 37^{\circ} \mathrm{C}\right)\end{array}$ & $36.4 \pm 9.50^{\mathrm{a}}$ & {$[31.1 ; 41.7]$} & $33.5 \pm 13.3^{\mathrm{a}}$ & {$[26.0 ; 40.9]$} & $35.7 \pm 13.2^{\mathrm{a}}$ & {$[28.3 ; 43.0]$} & $102 \pm 29.3^{b}$ & {$[86.2 ; 119]$} \\
\hline
\end{tabular}

${ }^{\mathrm{abc}}$ Different letters present significant differences between the different materials within one aging level 
Fig. 5 Graphical illustration of the retention force $[\mathrm{N}]$ of the different clasp materials at the three aging levels

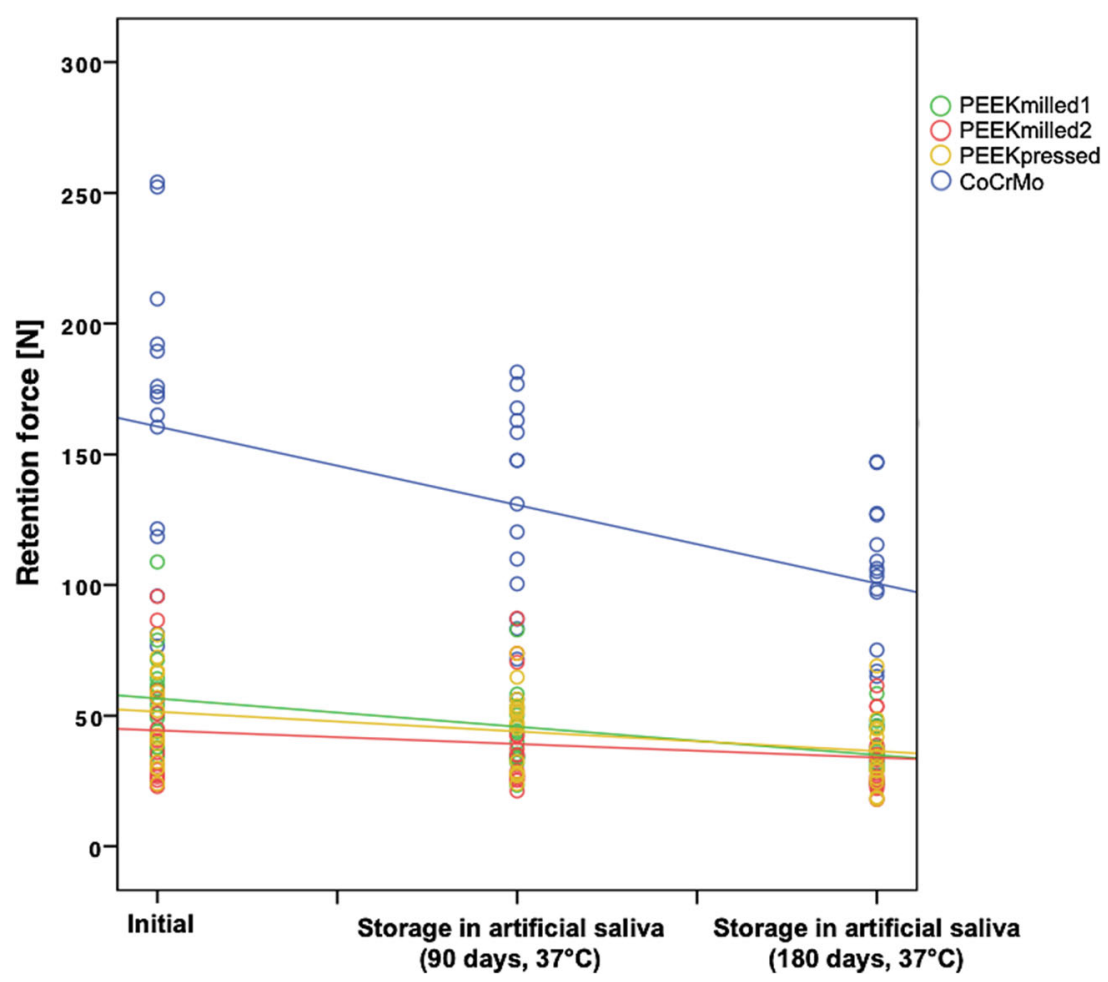

a prolonged aging process, which included cycles of repeated insertion and removal along both ideal and non-ideal paths in artificial saliva, while exhibiting inferior retention forces in comparison to conventional CoCr clasps [20].

Regarding clinical implications, PEEK materials might therefore represent the material of choice for anterior abutment teeth that possess little anatomical undercut and in consequence require little deformation during insertion and removal, while CoCrMo could be the material of choice for the posterior regions, where molars provide a large retentive area and high masticatory forces demand superior retentive capacities and functional stability [2]. Individual patient situations might thus call for individualized treatment planning regarding the choice of clasp material.

As of today, only few reports about PEEK's behavior in clinical conditions are available. According to one recently published case report with a 2-year follow-up period, PEEK shows promising results, as few color and texture changes of PEEK were found macroscopically. The clasp arm still fitted well without any deformation and a high subjective satisfaction was expressed by both the practitioner and the patient [39]. Further advantages include the low weight of PEEK prostheses, the tooth-similar color, a reportedly good fit and high retention $[40,41]$, and a protective effect on the periodontal ligament [42]. However, the indication of PEEK as a framework material remains controversial, as its stability in a free-end situation under masticatory forces is not conducive for a RDP's stability [42].

While this study observed promising results for PEEK materials in regard to their potential use as RDP clasps and their high resistance against artificial aging in saliva, this in vitro study does entail several limitations. Only a small number of

Table 4 Influence of a repetitive insertion and removal on the retention force $[\mathrm{N}]$ of the different clasp materials at varying aging levels

\begin{tabular}{|c|c|c|c|c|c|c|c|c|}
\hline \multirow[t]{2}{*}{ Aging level } & \multicolumn{2}{|c|}{ PEEKmilled1 } & \multicolumn{2}{|c|}{ PEEKmilled2 } & \multicolumn{2}{|c|}{ PEEKpressed } & \multicolumn{2}{|l|}{ CoCrMo } \\
\hline & Mean \pm SD & $95 \% \mathrm{CI}$ & Mean \pm SD & $95 \% \mathrm{CI}$ & Mean \pm SD & $95 \% \mathrm{CI}$ & Mean \pm SD & $95 \% \mathrm{CI}$ \\
\hline (1) Initial & $-1.7^{\mathrm{c}}$ & {$[-3.4 ;-0.02]$} & $7.5^{\mathrm{b}}$ & {$[6.4 ; 8.6]$} & $-4.8^{\mathrm{c}}$ & {$[-6.0 ;-3.5]$} & $14.8^{\mathrm{c}}$ & {$[11.3 ; 18.3]$} \\
\hline $\begin{array}{l}\text { (2) After storage in artificial saliva } \\
\left(90 \text { days, } 37^{\circ} \mathrm{C}\right)\end{array}$ & $-9.1^{b}$ & {$[-9.9 ;-8.2]$} & $-0.5^{\mathrm{b}}$ & {$[-1.2 ;-0.2]$} & $-1.3^{\mathrm{b}}$ & {$[-1.8 ;-0.7]$} & $-11.8^{\mathrm{b}}$ & {$[-14.4 ;-9.1]$} \\
\hline $\begin{array}{l}\text { (3) After storage in artificial saliva } \\
\left(180 \text { days, } 37^{\circ} \mathrm{C}\right)\end{array}$ & $-0.7^{\mathrm{a}}$ & {$[-1.2 ;-0.2]$} & $-6.4^{\mathrm{a}}$ & {$[-7.3 ;-5.5]$} & $-4.3^{\mathrm{a}}$ & {$[-5.0 ;-3.6]$} & $-6.8^{\mathrm{a}}$ & {$[-8.7 ;-4.8]$} \\
\hline
\end{tabular}

${ }^{\mathrm{abc}}$ Different letters present significant differences between aging levels within one material 
materials were tested in the present study. As the dental market moves quickly and new compositions are introduced each year, future studies will have to examine a wider range of materials. The use of artificial saliva furthermore only imitates one part of the manifold influences RDPs are exposed to during function, such as temperature changes or variations of the $\mathrm{pH}$ value. In the present study, only one clasp design, namely the popular Bonwill clasp, was examined. To allow the implementation of PEEK as a clasp material to a bigger extent, it is necessary to convey further examinations including a wide variety of clasp designs and geometries. As the environment has been reported to show varying effects on dislodging a clasp according to the type of clasp [43], and deformations differ due to the design of a clasp, future studies should focus on determining in how far PEEK materials could present a valid alternative to CoCrMo in specific situations, such as the esthetic anterior region presenting with little undercut, or periodontally damaged dentitions prone to the negative effects of excessively high retention forces [33]. The use of PEEK clasps could pave the way for a fully digital workflow in the treatment of patients with RDPs, from the digital impression to manufacturing using $\mathrm{CAD} / \mathrm{CAM}$ technology [34]. Highly time- and resources-consuming laboratory processes in the fabrication of CoCrMo clasps that due to their manual background are furthermore prone to mistakes could hereby be replaced by machine processing of PEEK materials ensuring a high homogeneity of the material and promising great esthetic results. Moreover, due to the high surface resistance of PEEK material, its low reactivity, and a highly inert behavior in the oral cavity, these materials could have a good prognosis for allergy prone patients [19, 24]. Further clinical as well as laboratory studies are necessary to confirm the present findings.

\section{Conclusions}

Within the limitations of this study, the following conclusions can be drawn:

1 Although the control group showed significantly higher results, the retention force values observed for PEEK materials indicate a potential clinical application.

2 The manufacturing process of PEEK did not influence the retention force.

3 While the control group was susceptible to artificial aging, PEEK materials presented constant results.

4 Ultimately, a repetitive insertion and removal of the clasps resulted in decreased retention force values.

Acknowledgments The authors would like to thank NT digital implant technology, bredent, and Dentaurum for supporting this study with material.
Funding Open Access funding enabled and organized by Projekt DEAL.

\section{Compliance with ethical standards}

Conflict of interest The authors declare that they have no conflict of interest.

Ethical approval This article does not contain any studies with human participants or animals performed by any of the authors.

Informed consent For this type of study, formal consent was not required.

Open Access This article is licensed under a Creative Commons Attribution 4.0 International License, which permits use, sharing, adaptation, distribution and reproduction in any medium or format, as long as you give appropriate credit to the original author(s) and the source, provide a link to the Creative Commons licence, and indicate if changes were made. The images or other third party material in this article are included in the article's Creative Commons licence, unless indicated otherwise in a credit line to the material. If material is not included in the article's Creative Commons licence and your intended use is not permitted by statutory regulation or exceeds the permitted use, you will need to obtain permission directly from the copyright holder. To view a copy of this licence, visit http://creativecommons.org/licenses/by/4.0/.

\section{References}

1. Wostmann B, Budtz-Jorgensen E, Jepson N, Mushimoto E, Palmqvist S, Sofou A, Owall B (2005) Indications for removable partial dentures: a literature review. Int J Prosthodont 18:139-145

2. Davenport JC, Basker RM, Heath JR, Ralph JP, Glantz PO, Hammond P (2001) Clasp design. Br Dent J 190:71-81. https:// doi.org/10.1038/sj.bdj.4800887

3. Osada H, Shimpo H, Hayakawa T, Ohkubo C (2013) Influence of thickness and undercut of thermoplastic resin clasps on retentive force. Dent Mater J 32:381-389. https://doi.org/10.4012/dmj.2012-284

4. Vallittu PK, Kokkonen M (1995) Deflection fatigue of cobalt-chromium, titanium, and gold alloy cast denture clasp. J Prosthet Dent 74:412-419. https://doi.org/10.1016/s0022-3913(05)80384-1

5. Ghani F, Mahood M (1990) A laboratory examination of the behaviour of cast cobalt-chromium clasps. J Oral Rehabil 17:229 237. https://doi.org/10.1111/j.1365-2842.1990.tb00003.x

6. Mahmoud A (2007) Pre-overloading to extend fatigue life of cast clasps. J Dent Res 86:868-872. https://doi.org/10.1177/ 154405910708600912

7. Mahmoud A, Wakabayashi N, Takahashi H, Ohyama T (2005) Deflection fatigue of Ti-6Al-7Nb, Co-Cr, and gold alloy cast clasps. J Prosthet Dent 93:183-188. https://doi.org/10.1016/j. prosdent.2004.11.011

8. Sato Y, Abe Y, Yuasa Y, Akagawa Y (1997) Effect of friction coefficient on Akers clasp retention. J Prosthet Dent 78:22-27. https://doi.org/10.1016/s0022-3913(97)70083-0

9. Sato Y, Tsuga K, Abe Y, Asahara S, Akagawa Y (2000) Dimensional measurement and finite element analysis of I-bar clasps in clinical use. J Oral Rehabil 27:935-939. https://doi.org/ 10.1046/j.1365-2842.2000.00621.x

10. Sato Y, Tsuga K, Abe Y, Asahara S, Akagawa Y (2001) Analysis of stiffness and stress in I-bar clasps. J Oral Rehabil 28:596-600. https://doi.org/10.1046/j.1365-2842.2001.00600.x 
11. Rodrigues RC, Ribeiro RF, de Mattos MG, Bezzon OL (2002) Comparative study of circumferential clasp retention force for titanium and cobalt-chromium removable partial dentures. J Prosthet Dent 88:290-296. https://doi.org/10.1067/mpr.2002.128128

12. Bridgeman JT, Marker VA, Hummel SK, Benson BW, Pace LL (1997) Comparison of titanium and cobalt-chromium removable partial denture clasps. J Prosthet Dent 78:187-193. https://doi.org/ 10.1016/s0022-3913(97)70124-0

13. Kola MZ, Raghav D, Kumar P, Alqahtani F, Murayshed MS, Bhagat TV (2016) In vitro assessment of clasps of cobaltchromium and nickel-titanium alloys in removable prosthesis. $\mathrm{J}$ Contemp Dent Pract 17:253-257. https://doi.org/10.5005/jpjournals-10024-1836

14. Byron R Jr, Frazer RQ, Herren MC (2007) Rotational path removable partial denture: an esthetic alternative. Gen Dent 55:245-250 quiz 251,264

15. Khan SB, Geerts GA (2005) Aesthetic clasp design for removable partial dentures: a literature review. SADJ 60:190-194

16. Moreno de Delgado M, Garcia LT, Rudd KD (1986) Camouflaging partial denture clasps. J Prosthet Dent 55:656-660. https://doi.org/ 10.1016/0022-3913(86)90050-8

17. Arda T, Arikan A (2005) An in vitro comparison of retentive force and deformation of acetal resin and cobalt-chromium clasps. J Prosthet Dent 94:267-274. https://doi.org/10.1016/j.prosdent. 2005.06.009

18. Tannous F, Steiner M, Shahin R, Kern M (2012) Retentive forces and fatigue resistance of thermoplastic resin clasps. Dent Mater 28: 273-278. https://doi.org/10.1016/j.dental.2011.10.016

19. Bathala L, Majeti V, Rachuri N, Singh N, Gedela S (2019) The role of polyether ether ketone (peek) in dentistry - a review. J Med Life 12:5-9. https://doi.org/10.25122/jml-2019-0003

20. Marie A, Keeling A, Hyde TP, Nattress BR, Pavitt S, Murphy RJ, Shary TJ, Dillon S, Osnes C, Wood DJ (2019) Deformation and retentive force following in vitro cyclic fatigue of cobalt-chrome and aryl ketone polymer (AKP) clasps. Dent Mater 35:e113-e121. https://doi.org/10.1016/j.dental.2019.02.028

21. Najeeb S, Zafar MS, Khurshid Z, Siddiqui F (2016) Applications of polyetheretherketone (PEEK) in oral implantology and prosthodontics. J Prosthodont Res 60:12-19. https://doi.org/10.1016/j.jpor.2015.10.001

22. Papathanasiou I, Kamposiora P, Papavasiliou G, Ferrari M (2020) The use of PEEK in digital prosthodontics: a narrative review. BMC Oral Health 20:217. https://doi.org/10.1186/s12903-02001202-7

23. Najeeb S, Bds ZK, Bds SZ, Bds MS (2016) Bioactivity and osseointegration of PEEK are inferior to those of titanium: a systematic review. J Oral Implantol 42:512-516. https://doi.org/10. 1563/aaid-joi-D-16-00072

24. Kurtz SM, Devine JN (2007) PEEK biomaterials in trauma, orthopedic, and spinal implants. Biomaterials 28:4845-4869. https://doi. org/10.1016/j.biomaterials.2007.07.013

25. Toth JM, Wang M, Estes BT, Scifert JL, Seim HB 3rd, Turner AS (2006) Polyetheretherketone as a biomaterial for spinal applications. Biomaterials 27:324-334. https://doi.org/10.1016/j. biomaterials.2005.07.011

26. Stawarczyk B, Eichberger M, Uhrenbacher J, Wimmer T, Edelhoff D, Schmidlin PR (2015) Three-unit reinforced polyetheretherketone composite FDPs: influence of fabrication method on load-bearing capacity and failure types. Dent Mater J 34:7-12. https://doi.org/10.4012/dmj.2013-345

27. Hahnel S, Henrich A, Burgers R, Handel G, Rosentritt M (2010) Investigation of mechanical properties of modern dental composites after artificial aging for one year. Oper Dent 35:412-419. https:// doi.org/10.2341/09-337-L

28. Fusayama T, Katayori T, Nomoto S (1963) Corrosion of gold and amalgam placed in contact with each other. J Dent Res 42:11831197. https://doi.org/10.1177/00220345630420051301
29. Peng TY, Ogawa Y, Akebono H, Iwaguro S, Sugeta A, Shimoe S (2019) Finite-element analysis and optimization of the mechanical properties of polyetheretherketone (PEEK) clasps for removable partial dentures. J Prosthodont Res 64:250-256. https://doi.org/10. 1016/j.jpor.2019.07.012

30. Tribst JPM, Dal Piva AMO, Borges ALS, Araujo RM, da Silva JMF, Bottino MA, Kleverlaan CJ, de Jager N (2020) Effect of different materials and undercut on the removal force and stress distribution in circumferential clasps during direct retainer action in removable partial dentures. Dent Mater 36:179-186. https://doi. org/10.1016/j.dental.2019.11.022

31. Torii M, Nakata T, Takahashi K, Kawamura N, Shimpo H, Ohkubo C (2018) Fitness and retentive force of cobalt-chromium alloy clasps fabricated with repeated laser sintering and milling. J Prosthodont Res 62:342-346. https://doi.org/10.1016/j.jpor.2018.01.001

32. Yamazaki T, Murakami N, Suzuki S, Handa K, Yatabe M, Takahashi H, Wakabayashi N (2019) Influence of block-out on retentive force of thermoplastic resin clasps: an in vitro experimental and finite element analysis. J Prosthodont Res 63:303-308. https://doi.org/10.1016/j.jpor.2019.01.002

33. Muller S, Eickholz P, Reitmeir P, Eger T (2013) Long-term tooth loss in periodontally compromised but treated patients according to the type of prosthodontic treatment. A retrospective study. J Oral Rehabil 40:358-367. https://doi.org/10.1111/joor.12035

34. Tallarico M (2020) Computerization and digital workflow in medicine: focus on digital dentistry. Materials (Basel) 13. https://doi. org $/ 10.3390 / \mathrm{ma} 13092172$

35. Lassila LV, Vallittu PK (1998) Effect of water and artificial saliva on the low cycle fatigue resistance of cobalt-chromium dental alloy. J Prosthet Dent 80:708-713. https://doi.org/10.1016/s00223913(98)70059-9

36. Gao S, Gao S, Xu B, Yu H (2015) Effects of different pH-values on the nanomechanical surface properties of PEEK and CFR-PEEK compared to dental resin-based materials. Materials (Basel) 8: 4751-4767. https://doi.org/10.3390/ma8084751

37. Al Jabbari YS (2014) Physico-mechanical properties and prosthodontic applications of Co-Cr dental alloys: a review of the literature. J Adv Prosthodont 6:138-145. https://doi.org/10.4047/jap.2014.6. 2.138

38. Schwitalla AD, Spintig T, Kallage I, Muller WD (2015) Flexural behavior of PEEK materials for dental application. Dent Mater 31: 1377-1384. https://doi.org/10.1016/j.dental.2015.08.151

39. Ichikawa T, Kurahashi K, Liu L, Matsuda T, Ishida Y (2019) Use of a polyetheretherketone clasp retainer for removable partial denture: a case report. Dent J (Basel) 7. https://doi.org/10.3390/dj7010004

40. Harb IE, Abdel-Khalek EA, Hegazy SA (2019) CAD/CAM constructed poly(etheretherketone) (PEEK) framework of Kennedy Class I Removable Partial Denture: a clinical report. J Prosthodont 28:e595-e598. https://doi.org/10.1111/jopr.12968

41. Zoidis P, Papathanasiou I, Polyzois G (2016) The use of a modified poly-ether-ether-ketone (PEEK) as an alternative framework material for removable dental prostheses. A Clinical Report. J Prosthodont 25:580-584. https://doi.org/10.1111/jopr.12325

42. Chen X, Mao B, Zhu Z, Yu J, Lu Y, Zhang Q, Yue L, Yu H (2019) A three-dimensional finite element analysis of mechanical function for 4 removable partial denture designs with 3 framework materials: CoCr, Ti-6Al-4V alloy and PEEK. Sci Rep 9:13975. https://doi. org/10.1038/s41598-019-50363-1

43. Mourshed B, Qaed NM, Al-Shamiri HM, Alaizari N, Alhamdah SS, Alfaqih A (2017) The effect of environment (dry and natural saliva) on clasp retention: in vitro study - part I. Eur J Dent 11:352356. https://doi.org/10.4103/ejd.ejd_158_17

Publisher's note Springer Nature remains neutral with regard to jurisdictional claims in published maps and institutional affiliations. 